\title{
Left atrial ball thrombus associated with severe left ventricular dysfunction due to aortic valve stenosis in a patient on dialysis
}

\author{
Masato Nakajima, MD, Koji Tsuchiya, MD, Yuki Okamoto, MD, Kiyotaka Yano, MD, and Tatsuho Kobayashi, MD, \\ Kofu City, Japan
}

Left atrial ball thrombus is frequently associated with mitral valve disease and atrial fibrillation. Only a few cases of left atrial ball thrombus associated with restrictive cardiomyopathy in the absence of mitral valve disease have been previously reported. In the present case report, left atrial ball thrombus developed in a patient with aortic valve stenosis, severe left ventricular dysfunction, and chronic renal failure requiring hemodialysis. To our knowledge, this is a unique report of left atrial ball thrombus caused by severe left ventricular dysfunction due to aortic valve stenosis in the presence of sinus rhythm.

\section{CLINICAL SUMMARY}

A 77-year-old woman was referred to our hospital for surgical treatment of aortic valve stenosis with severe left ventricular dysfunction. The patient had an 8-year history of hemodialysis for chronic renal failure and presented with an approximately 1-year history of worsening exertional dyspnea. Transthoracic echocardiography (TTE) revealed a severely calcified aortic valve with an estimated pressure gradient of $75.2 \mathrm{~mm} \mathrm{Hg}$ and left ventricular dilatation and global dysfunction with a diastolic dimension of $63 \mathrm{~mm}$, a systolic dimension of $58 \mathrm{~mm}$, and a fractional shortening of 0.17. Intracardiac thrombus was not detected out at the time of the initial TTE. Aortic valve replacement was performed electively approximately 2 weeks after the TTE evaluation.

At the operation, transesophageal echocardiography (TEE) revealed a calcified aortic valve and a floating ball thrombus in the left atrial cavity, which was about $40 \mathrm{~mm}$ in diameter (Figure 1). Therefore, thrombus removal and aortic valve replacement with a 21-mm mechanical valve (SJM Regent, St Paul, Minn) were performed concomitantly (Figure 2). The aortic valve was calcified bicuspid, and the ball thrombus was attached to the interatrial septum with

From the Department of Cardiovascular Surgery, Yamanashi Central Hospital, Kofu City, Yamanashi, Japan.

Received for publication Dec 4, 2007; revisions received Dec 21, 2007; accepted for publication Dec 24, 2007.

Address for reprints: Masato Nakajima, MD, Yamanashi Central Hospital, Cardiovascular Surgery, 1-1-1 Fujimi, Kofu City, Yamanashi 400-0027, Japan (E-mail: m-nakajima2a@ych.pref.yamanashi.jp).

J Thorac Cardiovasc Surg 2009;137:756-7

$0022-5223 / \$ 36.00$

Copyright (C) 2009 by The American Association for Thoracic Surgery

doi:10.1016/j.jtcvs.2007.12.090

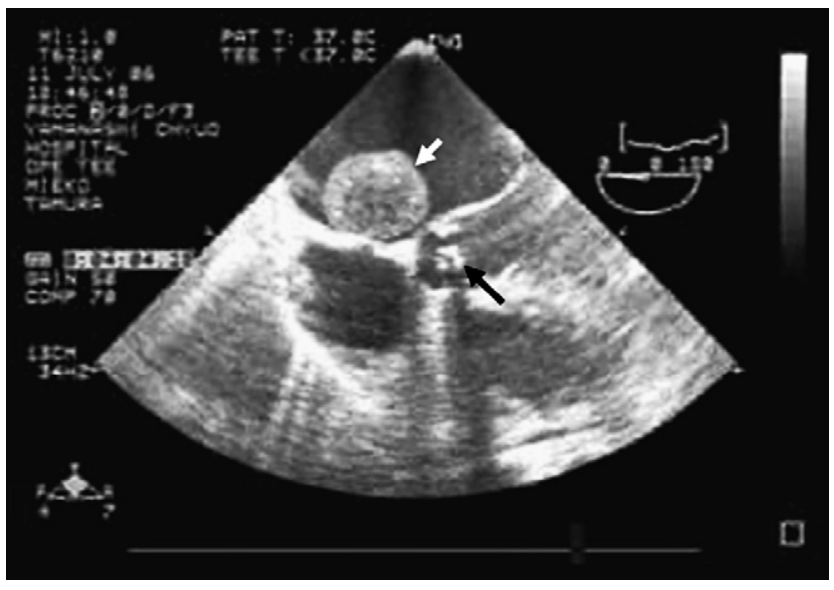

FIGURE 1. Preoperative transesophageal echocardiography showed a calcified aortic valve (black arrow) and a ball thrombus in the left atrial cavity, which was about $40 \mathrm{~mm}$ in diameter (white arrow).

a 2-mm width. The patient recovered well and was discharged from the hospital without complications. The patient received anticoagulation with warfarin postoperatively and has been doing well without thromboembolic complications for 15 months.

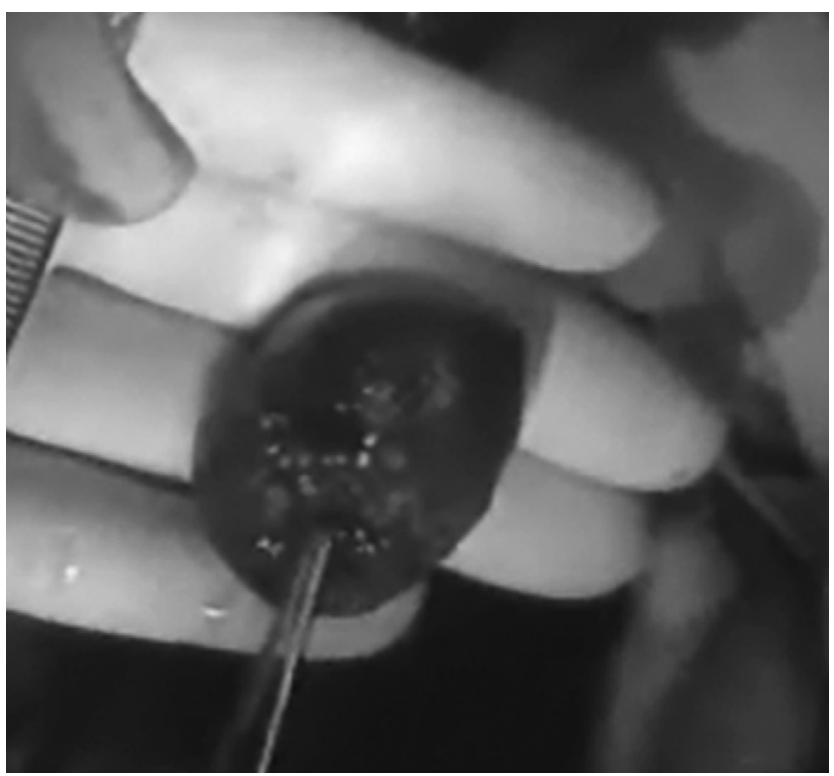

FIGURE 2. The left atrial ball thrombus was removed prior to the aortic valve procedure. 


\section{DISCUSSION}

Left atrial ball thrombus is infrequent but well recognized as a catastrophic complication of long-standing mitral valve disease and atrial fibrillation. ${ }^{1,2}$ Recent development of reliable methods for identifying the presence of left atrial ball thrombus, such as TEE, computed tomography, and magnetic resonance imaging, has contributed to early diagnosis and prompt treatment for preventing catastrophic embolic complications. However, left atrial ball thrombus not associated with mitral valve disease and atrial fibrillation is extremely rare. Left atrial enlargement secondary to a low cardiac output and high atrial filling pressure might cause thrombus formation in the left atrial cavity. In fact, left atrial thrombi that developed in patients with restrictive cardiomyopathy was previously reported. ${ }^{3,4}$ Furthermore, in patients with severe left ventricular dysfunction due to valvular or ischemic heart disease, there is a possibility of thrombus formation in the cardiac chambers. In the present patient, the left ventricular dysfunction due to severe aortic valve stenosis may have led to thrombus formation even in the presence of sinus rhythm. However, rapid growth of this ball thrombus is thought to have a connection with other factors.

The relative risk of left atrial ball thrombus in patients requiring hemodialysis for chronic renal failure remains unclear. Nishimura and his colleagues ${ }^{5}$ reported a high incidence of left atrial appendage thrombus in patients on maintenance hemodialysis. The process of hemodialysis itself is more strongly associated with thrombosis than the state of chronic renal failure because of activation of neutrophils, monocytes, and platelets from contact with the hemodialysis membrane. Therefore, it was thought that hemodialysis might affect the thrombus formation in the present patient.

This is a unique report of left atrial ball thrombus caused by severe left ventricular dysfunction due to aortic valve stenosis in the presence of sinus rhythm. Left atrial ball thrombus should be considered in patient with severe left ventricular dysfunction even though mitral valve disease or atrial fibrillation is not recognized.

\section{References}

1. Wrisley D, Giambartolomei A, Lee I, Brownlee W. Left atrial ball thrombus: review of clinical and echocardiographic manifestations with suggestions for management. Am Heart J. 1991;121:1784-90.

2. Tsioufis CP, Stefanadis CI, Tsiamis EG, Kallikazaros IE, Toutouzas PK. A free floating ball thrombus in the left atrial cavity. J Thorac Cardiovasc Surg. 1999;118:1120-2.

3. Turhan H, Ocal A, Erbay AR, Yasar AS, Cicekcioglu F, Yetkin E. Free-floating left atrial ball thrombus developed in an 11-year old child with restrictive cardiomyopathy during sinus rhythm: manifested as a major thromboembolic event. Int J Cardiol. 2005;101:111-3.

4. Arslan S, Serdar S, Gundogdu F. Fatal biatrial thrombus in a patient with idiopathic restrictive cardiomyopathy during sinus rhythm. Int $J$ Cardiol. 2007;117:e68-70.

5. Nishimura M, Hashimoto T, Kobayashi H, Fukada T, Okino K, Yamamoto N, et al The high incidence of left atrial appendage thrombosis in patients on maintenance haemodialysis. Nephrol Dial Transplant. 2003;18:2239-47.

\title{
Long-term cardiac remodeling after salvage partial left ventriculectomy in an infant with anomalous left coronary artery from the pulmonary artery
}

\author{
Stephen Westaby, PhD, MS, FETCS, FECS, FACC, ${ }^{\text {a }}$ Nick Archer, MD, ${ }^{\mathrm{b}}$ and Saul G. Myerson, MD, MRCP, FESC, ${ }^{\mathrm{c}}$ \\ Oxford, United Kingdom
}

Anomalous left coronary artery from the pulmonary artery (ALCAPA) is an unusual cause of heart failure in infancy. ${ }^{1}$ In this anomaly, left coronary blood flow is reversed with

\footnotetext{
From the Departments of Cardiothoracic Surgery, ${ }^{\mathrm{a}}$ Paediatric Cardiology, ${ }^{\mathrm{b}}$ Cardiovascular Medicine, ${ }^{\mathrm{c}}$ University of Oxford, John Radcliffe Hospital, Oxford, United Kingdom.

Received for publication Dec 13, 2007; revisions received Feb 22, 2008; accepted for publication March 23, 2008.

Address for reprints: Dr Stephen Westaby, Dept. of Cardiothoracic Surgery, John Radcliffe Hospital, Headley Way, Oxford OX3 9DU, UK. (E-mail: swestaby@ ahf.org.uk).

J Thorac Cardiovasc Surg 2009;137:757-9

$0022-5223 / \$ 36.00$

Copyright (C) 2009 by The American Association for Thoracic Surgery

doi:10.1016/j.jtcvs.2008.03.068
}

steal into the pulmonary artery. Repeated episodes of myocardial ischemia or infarction cause globally impaired left ventricular function and may substantially increase the risk of surgical correction. In this report, we provide late follow-up on an infant with ALCAPA, who following coronary reimplantation could not be separated from cardiopulmonary bypass. In the absence of circulatory support technology, radical left ventricular remodeling was undertaken with successful results.

\section{CLINICAL SUMMARY}

A 5-month-old female infant presented with heart failure manifested by breathlessness and failure to thrive. 